\title{
A Study of Endometrial Perfusion in Unexplained Infertility
}

\section{Ahmad Mohammed Nour-Eldin Hashad, Heba Abdel Naby Kamal Elkholy ${ }^{3}$, Mohamed Kamal Etman $^{2}$, Ibrahim Mohamed Ibrahim ${ }^{1}$}

\author{
${ }^{1}$ Obstetrics \& Gynecology Department, Ain Shams University, ${ }^{2}$ Ultrasound Special Care Unit for the Fetus, \\ ${ }^{3}$ Cairo University
}

Corresponding author: Heba Abdel Naby Kamal Elkholy, email: drhebaelkholy@yahoo.com, Tele: 01006539415

\begin{abstract}
Background: Infertility in itself represents a wide spectrum of disorders explaining the inability to conceive. Series of investigations are required to depict the potential cause of infertility, yet there exist a small percentage $(10-25 \%)$ of couples in which no obvious cause is delineated. these groups of patients are classified as 'unexplained infertility. The endometrium has dynamic features: cyclical growth, desquamation and regeneration. Its main function is to provide the possibility of the time-limited support of implantation of the embryo for further development. Most part of the menstrual cycle, the endometrium is resistant to the embryo but acquires special receptive properties in a limited space and time interval of the luteal phase, known as the "implantation window".

Aim: The aim of this study was to evaluate the uterine perfusion, particularly the endometrial blood flow in women with unexplained infertility.

Methodology: The patients recruited from women presenting to the outpatient clinic at Ain Shams University Maternity Hospital seeking fertility compared to other fertile group coming to hospital with non specific gynecological problems or for routine checkup at the same period. The study conducted on two groups of women: Group1(study group) 40 women with unexplained infertility, Group 2 (control group) 20 fertile women who had normal physical and pelvic examination, regular menstrual cycles, didn't have intrauterine device or oral contraceptive, and gave a birth year ago.

Results: As regard the mean, the resistance index in the study group was 0.69 ranged from 0.39 to 0.96 , while the resistance index in the control group was 0.61 ranged from 0.58 to 0.73 and the difference between both groups was statistically significant pulsatility index in the study group was 1.3 ranged from 0.51 to 1.99 while the pulsatility index in the control group was 1.16 ranged from 0.88 to 1.7 and this difference between both groups was statistically significant. From the results of our study we could say that uterine perfusion, particularly the endometrial blood flow in women with unexplained infertility different from that in fertile women.

Recommendation: We recommend further study on large numbers of women and the possible role of perfusion enhancer's drugs in improving utero-ovarian circulation as a treatment of unexplained infertility.
\end{abstract}

Keywords: Endometrial perfusion, unexplained infertility

\section{INTRODUCTION}

Infertility in itself represents a wide spectrum of disorders explaining the inability to conceive. Series of investigations are required to depict the potential cause of infertility, yet there exist a small percentage $(10-25 \%)$ of couples in which no obvious cause is delineated. these groups of patients are classified as 'unexplained infertility ${ }^{(\mathbf{1})}$.

A number of studies showed that poor uterine and ovarian blood flow can be an important - often undiagnosed factor - in infertility, miscarriage and IVF failure; research shows that poor blood flow may be at the root of 'unexplained infertility' too. However, most women with a diagnosis of 'unexplained' would never be offered the diagnostic test for uterine blood flow impairment and would never be offered treatment, instead they would retain their frustrating nonspecific diagnosis of 'unexplained'(2).
Ultrasonography has an increasingly important role in the evaluation and treatment of infertility patients, being an efficient and costeffective modality for studying the female reproductive organs and for monitoring functional changes during spontaneous and induced cycles ${ }^{(3)}$.

During spontaneous menstrual cycles endometrial volume increased significantly during the follicular phase, reaching a plateau around the time of ovulation and remaining relatively stable throughout the luteal phase. ${ }^{(\mathbf{1})}$

Uterine arterial resistance changes might reflect receptivity of endometrium, so color Doppler signals are measured at the uterine arteries and their ascending branches located in the outer third of the myometrium ${ }^{(4)}$.

Uterine spiral artery perfusion has been found to improve during the luteal phase, which coincides with the implantation window ${ }^{(5)}$. 
Impedance of uterine and spiral arteries blood flow change periodically during the normal ovulatory menstrual cycle. Endometrial receptivity is regulated by many factors including uterine perfusion. Several studies have shown that uterine receptivity is decreased when the uterine artery impedance has been increased during the midluteal phase. Abnormal uterine perfusion may be a contributing factor to etiopathology of infertility especially in couples with unexplained infertility. Transvaginal Doppler pulsed ultrasound is an important tool for examining the female reproductive system and is a non-invasive method to assess the uterine perfusion ${ }^{(\mathbf{1})}$.

It is interesting that the lowest impedance at spiral artery blood flow has been detected just at the time at mid-luteal phase, during which endometrium has been transformed from proliferative phase to secretory phase. At this specific time period blood supply of uterus is rich and implantation is most likely to occur ${ }^{(6)}$.

In addition to this it was reported that impedance of spiral artery blood flow in women with unexplained infertility was significantly higher than that of the fertile counterparts similarly suggested that decreased uterine perfusion might be a cause of unexplained infertility ${ }^{(4)}$.

\section{AIM OF THE WORK}

The aim of this study is to evaluate the uterine perfusion, particularly the endometrial blood flow in women with unexplained infertility.

\section{PATIENTS AND METHODS}

Study population: The patients participated in our study were recruited from women presenting to the outpatient clinic at Ain Shams University Maternity Hospital seeking fertility were compared to other fertile group coming to hospital with nonspecific gynecological problems or for routine checkup at the same period.

Study duration: The study carried out during the period from June 2015 to April 2016. The study was approved by the Ethics Board of Ain Shams University.

Inclusion criteria: 1-Age less than 40 years. 2-Not smoker. 3-Didn't have any systemic or medical disease. 4-Transvaginal ultrasound, midluteal phase progesterone value, hysterosalpingography and detailed semen analysis are normal in the study group. 5-Did not have intrauterine device or use oral contraception in fertile group.

Exclusion criteria: 1-Age above 40. 2Smoker. 3-Have medical or gynecological problems.

Ethics: The study was approved from the Ethical Committee of the Department of Obstetrics and Gynecology, Faculty of Medicine, Ain-Shams University.

\section{Patient information and informed consent:}

Before being admitted to the study, the patient consented to participate after the nature, scope, and possible consequences of the clinical study have been explained in a form understandable to her. An informed consent document, in Arabic language, contains all locally required elements and specifies who informed the patient. After reading the informed consent document, the patient gave consent in writing. The patient's consent confirmed at the time of consent by the personally dated signature of the patient and by the personally dated signature of the person conducting the informed consent discussions.

Those patients who are unable to read, oral presentation and explanation of the written informed consent form and information supplied to patients in the presence of an impartial witness. Consent was confirmed at the time of consent orally and by the personally dated signature of the patient or by a local legally recognized alternative (e.g., the patient's thumbprint or mark). The witness and the person conducting the informed consent discussions also signed and personally dated the consent document. The original signed consent document was retained by the investigator. The investigator was not undertaking any measures specifically required only for the clinical study until valid consent has been obtained.

Before the beginning of the study and in accordance with the local regulation followed, the protocol and all corresponding documents were declared for Ethical and Research approval by the Council of OB/GYN Department, Ain Shams University.

This study was conducted on two groups of women: Group 1 (study group): 40 women with unexplained infertility. Group 2 (control group): 20 fertile women who had normal physical and pelvic examination, regular menstrual cycles, didn't have intrauterine device or oral contraceptive, and gave a birth year ago. 
Method:

\section{All patients in our study were subjected to:}

1-Detailed full history: Including age, parity, last menstrual period. Medical, surgical, family and drug history. History of present illness or any gynecological or urinary tract symptoms.

2- Complete general examination including: Blood pressure, temperature, pulse. Breast. Chest. Thyroid. Lower limb.

3- Laboratory investigation in the form of: Mid-luteal progesterone level. F.S.H, L.H, Prolactin. Semen analysis of husband.

\section{Indices of Uterine Artery Waveform Analysis:}

Uterine artery Doppler waveforms are most commonly analyzed by simple semi quantitative techniques based on analysis of the maximum Doppler shift frequencies of the time-velocity waveform, which varies during the cardiac cycle. Evaluation of the change in maximal Doppler shifts over time provides information on the impedance of the circulatory bed being fed. Time velocity waveform with high diastolic are seen when downstream resistance is low, and those with low or reverse diastolic flow are found when downstream resistance is high. The heart rate can significantly modify the waveform: high heart rates shorten the diastolic runoff time, producing high enddiastolic frequency shifts; low heart rates have an opposite effect ${ }^{(7)}$.

There are three widely used semi quantitative techniques for analysis of uterine artery waveforms:

The pulsatility index (PI): It is the most complex of the three. It has an advantage when analyzing complex waveforms that have absent or reverse flow. It is equal to peak systole minus end diastole divided by the mean value of the area under the curve over one cardiac cycle: (S-D)/mean velocity. When uterine circulation resistance is high, the uterine artery waveform has shorter upstroke and down stroke times and an early diastolic notch. Infrequently, there is absent early diastolic flow or reverse flow of the main uterine artery. These characteristics can be incorporated in the waveform analysis if one uses the PI but not when other, simpler methods are utilized ${ }^{\left({ }^{(8)}\right.}$

The resistance index (RI): Also called Pourcelot ratio. All that required here is measurement of peak systole and end diastole. It is equals to $(\mathrm{S}-\mathrm{D}) / \mathrm{S}^{(\mathbf{8}) \text {. }}$
The systolic/diastolic ratio (S/D): It is the simplest form of uterine waveform analysis. The main problem is that it becomes infinity when there is no or reversed end- diastolic velocity. The other obstacle is its nonparametric distribution at high values, which could be a problem because there are many occasions in the presence of severe preeclampsia where uterine artery (S/D) ratios are greater than $5.0^{(7)}$.

After the women agreed to participate in our study and sign the consent: Mid-luteal phase spiral artery parameters by using Medison X6 Ultrasound machine with a 4-9 $\mathrm{MHz}$ endovagianl transducer was measured. The uterus was scanned in the sagittal plane and the probe was directed to the lateral fornix to identify the ascending branch of the uterine artery in the para-cervical area at the level of the internal os. The pulsed Doppler wave was activated and the angle of insonation was adjusted to obtain three consequent similar waves. The blood flow resistant and pulsation indices of the uterine artery were visualized. The resistant and pulsation indices of the uterine artery were displayed on the monitor and the mean calculated. The Doppler ultrasonography was done by the same sonographer who was blind to the diagnosis of the particular patients. 3 readings were taken for every patient and we took the average to decrease the intraobserver variations.

Primary outcome: It was the difference between endometrial perfusion in unexplained infertile women and fertile ones.

Sample size justification: Group sample size of 20 fertile patients and 40 patients of unexplained infertility achieve $81 \%$ power to detect a different of 0.1 between the null hypothesis of both groups means are 0.5 and the alternative hypothesis of the mean of group 2 is 0.5 with estimated group standard deviation of 0.1 and with a significance level (alpha) of 0.05000 using a two-sided Mann-Whitney test assuming that the actual distribution is normal.

\section{Statistical analysis:}

Data were analyzed using Statistical Program for Social Science (SPSS) version 20.0. Quantitative data were expressed as mean \pm standard deviation (SD). Unpaired Student T-test was used to compare between two groups in quantitative data. Pearson's correlation coefficient (r) test was used for correlating data. Receiver operating characteristic (ROC curve) analysis was used to find out the overall predictivity of parameter in and to find out the best cut-off value with detection of sensitivity and specificity at this cut-off value. 


\section{RESULTS}

Table (1): All parameter descriptive of the study group.

\begin{tabular}{|l|c|c|}
\hline \multicolumn{1}{|c|}{ Group A: Study } & Mean & \\
\hline Age (years) & 26.28 & 4.11 \\
\hline BMI [wt/(ht)2] & 28.00 & 4.17 \\
\hline FSH (basal) mlU/mL & 7.95 & 1.68 \\
\hline LH & 4.31 & 1.42 \\
\hline Prolactin & 8.13 & 2.48 \\
\hline Mild-luteal progesterone (ng/mL) & 13.24 & 3.71 \\
\hline Resistance index & 0.69 & 0.12 \\
\hline Pulsatility index & 1.30 & 0.41 \\
\hline
\end{tabular}

Data are expressed as mean \pm standard deviation (SD)

Table (2): All parameter descriptive of the control group.

\begin{tabular}{|l|c|c|c|c|}
\hline \multicolumn{1}{|c|}{ Group B: Control } & Min. & Max. & Mean & \pm SD \\
\hline Age (years) & 20 & 35 & 27.35 & 3.80 \\
\hline BMI [wt/(ht)2] & 13.6 & 35.4 & 27.38 & 5.31 \\
\hline FSH (basal) $\mathrm{mlU} / \mathrm{mL}$ & 6.3 & 11.2 & 8.75 & 1.26 \\
\hline LH & 2.2 & 5.6 & 4.01 & 0.93 \\
\hline Prolactin & 2.9 & 14.6 & 8.77 & 2.39 \\
\hline Mild-luteal progesterone (ng/mL) & 9.2 & 18.9 & 14.21 & 3.28 \\
\hline Resistance index & 0.58 & 0.73 & 0.61 & 0.04 \\
\hline Pulsatility index & 0.88 & 1.7 & 1.16 & 0.24 \\
\hline
\end{tabular}

Data are expressed as mean \pm standard deviation (SD)

Table (3): Comparison between study and control according to age (years) and BMI.

\begin{tabular}{|c|c|c|c|c|}
\hline & Group A: Study & Group B: Control & t-test & p-value \\
\hline Age (years) & & & & \\
\hline Mean & $26.28 \pm 4.11$ & $27.35 \pm 3.80$ & \multirow{2}{*}{0.956} & \multirow{2}{*}{0.332} \\
\hline Range & $19-34$ & $20-35$ & & \\
\hline BMI [wt/(ht)2] & & & & \\
\hline Mean \pm SD & $28.00 \pm 4.17$ & $27.38 \pm 5.31$ & 0.252 & 0.618 \\
\hline Range & $20.4-36.3$ & $13.6-35.4$ & & \\
\hline
\end{tabular}

This table shows no statistically significant difference between study and control according to age and BMI.

Table (4): Comparison between study and control according to hormones.

\begin{tabular}{|c|c|c|c|c|}
\hline Hormones & Group A: Study & Group B: Control & t-test & $\mathrm{p}$-value \\
\hline \multicolumn{5}{|l|}{ FSH } \\
\hline Mean \pm SD & $7.95 \pm 1.68$ & $8.75 \pm 1.26$ & \multirow{2}{*}{3.535} & \multirow{2}{*}{0.065} \\
\hline Range & $4.6-11.5$ & $6.3-11.2$ & & \\
\hline \multicolumn{5}{|l|}{$\mathrm{LH}$} \\
\hline Mean \pm SD & $4.31 \pm 1.42$ & $4.01 \pm 0.93$ & \multirow{2}{*}{0.720} & \multirow{2}{*}{0.400} \\
\hline Range & $2.5-9.1$ & $2.2-5.6$ & & \\
\hline \multicolumn{5}{|l|}{ Prolactin } \\
\hline Mean \pm SD & $8.13 \pm 2.48$ & $8.77 \pm 2.39$ & \multirow{2}{*}{0.448} & \multirow{2}{*}{0.506} \\
\hline Range & $2.1-16.8$ & $2.9-14.6$ & & \\
\hline \multicolumn{5}{|c|}{ Mild-luteal progesterone } \\
\hline Mean \pm SD & $13.24 \pm 3.71$ & $14.21 \pm 3.28$ & \multirow{2}{*}{0.986} & \multirow{2}{*}{0.325} \\
\hline Range & $6.5-23.1$ & $9.2-18.9$ & & \\
\hline
\end{tabular}

This table shows no statistically significant difference between study and control according to hormones.

Table (5): Comparison between study and control according to resistance index.

\begin{tabular}{|c|c|c|c|c|}
\hline $\begin{array}{c}\text { Resistance } \\
\text { Index }\end{array}$ & $\begin{array}{c}\text { Group A: } \\
\text { Study }\end{array}$ & $\begin{array}{c}\text { Group B: } \\
\text { Control }\end{array}$ & t-test & $\begin{array}{c}\text { p- } \\
\text { value }\end{array}$ \\
\hline Mean \pm SD & $0.69 \pm 0.12$ & $0.61 \pm 0.04$ & 3.616 & 0.022 \\
\hline
\end{tabular}

This table shows statistically significant difference between study and control according to resistance index.

Table (6): Comparison between study and control according to pulsatility index.

\begin{tabular}{|l|c|c|c|c|}
\hline $\begin{array}{c}\text { Pulsatility } \\
\text { Index }\end{array}$ & $\begin{array}{c}\text { Group A: } \\
\text { Study }\end{array}$ & $\begin{array}{c}\text { Group B: } \\
\text { Control }\end{array}$ & t-test & $\begin{array}{c}\text { p- } \\
\text { value }\end{array}$ \\
\hline Mean \pm SD & $1.30 \pm 0.41$ & $1.16 \pm 0.24$ & 3.760 & 0.018 \\
\hline Range & $0.51-1.99$ & $0.88-1.7$ & 260 \\
\hline
\end{tabular}

This table shows statistically significant difference between study and control according to pulsatility index.

Table (7): Correlation between resistance index, pulsatility index and other parameters, using Pearson Correlation Coefficient, in study group.

\begin{tabular}{|l|c|c|c|c|}
\hline \multirow{2}{*}{\multicolumn{1}{|c|}{ Parameters }} & \multicolumn{2}{|c|}{ Resistancy index } & \multicolumn{2}{c|}{ Pulsatility index } \\
\cline { 2 - 5 } & $\mathrm{r}$ & $\begin{array}{c}\mathrm{p}- \\
\text { value }\end{array}$ & $\mathrm{r}$ & $\begin{array}{c}\mathrm{p}- \\
\text { value }\end{array}$ \\
\hline Age (years) & -0.078 & 0.554 & 0.089 & 0.499 \\
\hline BMI [wt/(ht)2] & 0.248 & 0.039 & 0.278 & 0.032 \\
\hline FSH (basal) $\mathrm{mlU} / \mathrm{mL}$ & 0.048 & 0.767 & -0.119 & 0.466 \\
\hline LH & -0.313 & 0.045 & -0.317 & 0.046 \\
\hline Prolactin & 0.133 & 0.414 & 0.022 & 0.891 \\
\hline $\begin{array}{l}\text { Mild-luteal progesterone } \\
\text { (ng/mL) }\end{array}$ & 0.183 & 0.259 & -0.082 & 0.613 \\
\hline
\end{tabular}

r- Pearson Correlation Coefficient

Negative correlation between LH and RI, PI and significant between resistance index \& pulsatility index with BMI and LH.

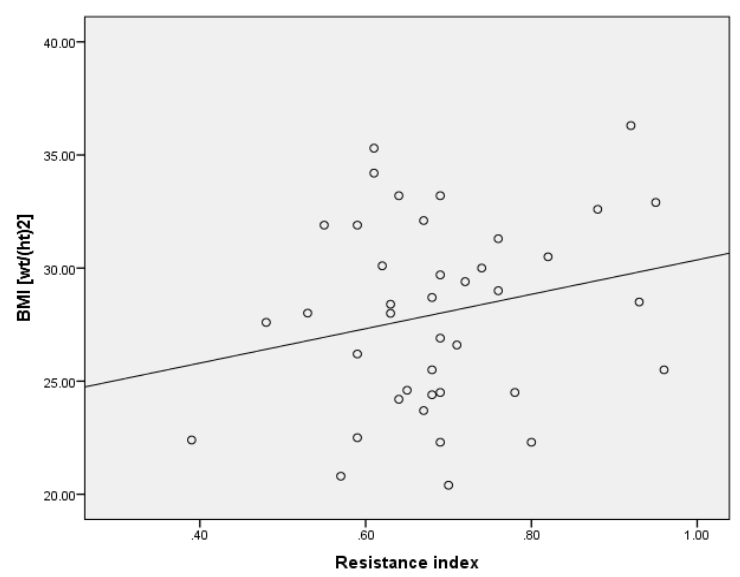

Fig. (1): Scatter plot between resistance index and BMI. 


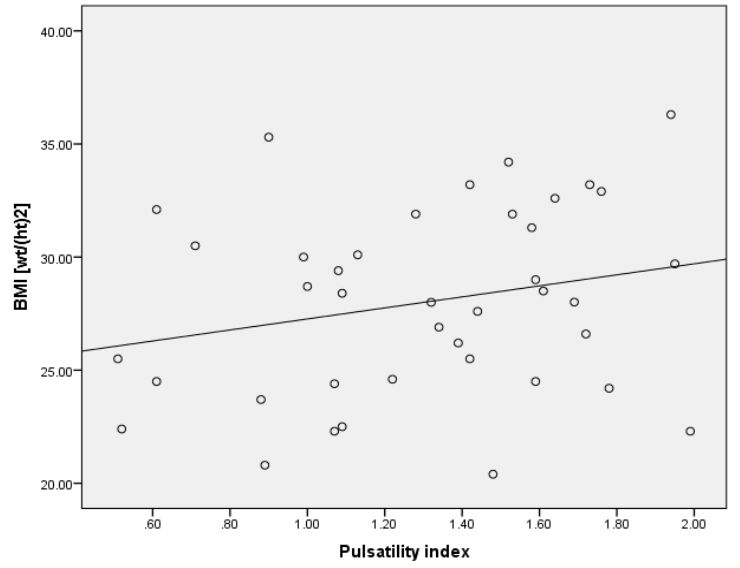

Fig. (2): Scatter plot between pulsatility index and BMI.

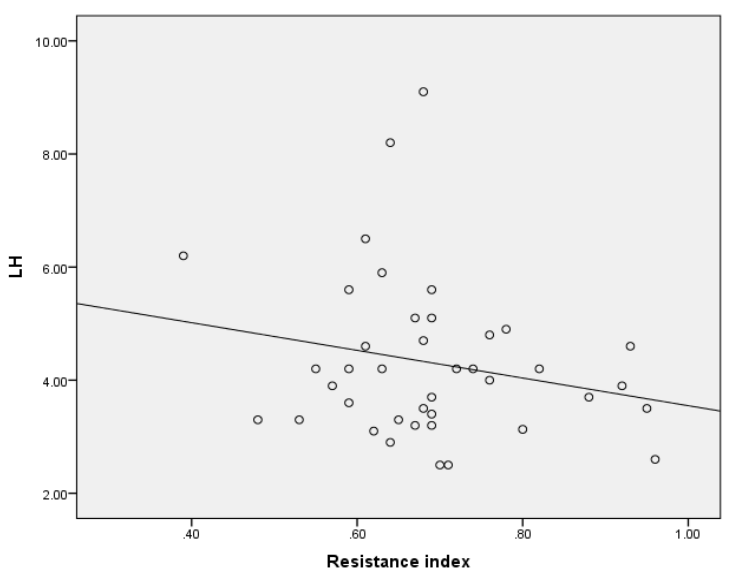

Fig. (3): Scatter plot between resistance index and LH.

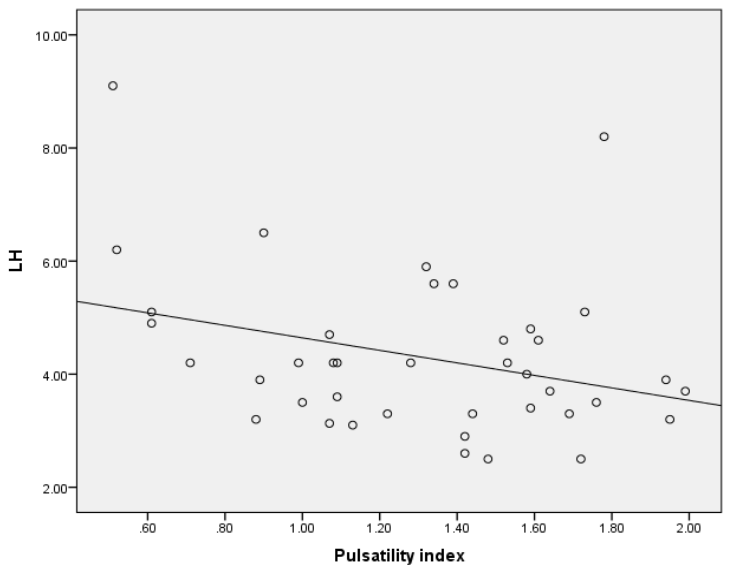

Fig. (4): Scatter plot between pulsatility index and LH.

Table (8): Diagnostic Performance of PI and RI in discrimination of patients and control.

\begin{tabular}{|c|c|c|c|c|c|c|}
\hline Item & Cut-off & Sen. & Spe. & PPV & NPV & Accuracy \\
\hline RI & $>0.67$ & $70 \%$ & $75 \%$ & $85 \%$ & $60 \%$ & $69.7 \%$ \\
\hline PI & $>1.37$ & $77.5 \%$ & $85 \%$ & $87 \%$ & $66 \%$ & $85.3 \%$ \\
\hline
\end{tabular}

Receiver operating characteristics (ROC) curve was used to define the best cut off value of:

RI: which was $>0.67$, with sensitivity of $70 \%$ specificity of $75 \%$ positive predictive value of $85 \%$, negative predictive value of $60 \%$ with diagnostic accuracy of $69.7 \%$.

PI: which was $>1.37$, with sensitivity of $77.5 \%$ specificity of $85 \%$ positive predictive value of $87 \%$, negative predictive value of $66 \%$ with diagnostic accuracy of $85.3 \%$.

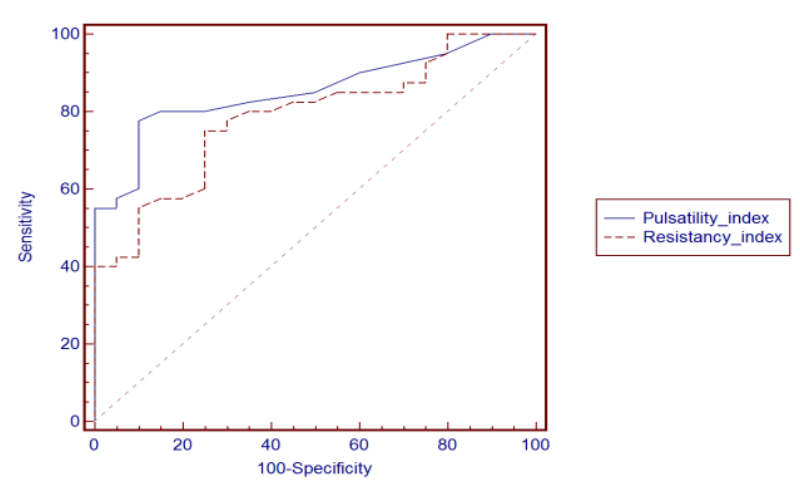

Fig. (5): Receiver-operating characteristic (ROC) curve for PI and RI in discrimination of patients and control.

\section{DISCUSSION}

The endometrium has dynamic features: cyclical growth, desquamation and regeneration. Its main function is to provide the possibility of the time-limited support of implantation of the embryo for further development. Most part of the menstrual cycle, the endometrium is resistant to the embryo but acquires special receptive properties in a limited space and time interval of the luteal phase, known as the "implantation window" (9).

It has been previously demonstrated that impedance of uterine and spiral arteries blood flow changes periodically during the normal ovulatory menstrual cycle ${ }^{(\mathbf{1 0})}$.

It is interesting that the lowest impedance at spiral artery blood flow has been detected just at the time at mid-luteal phase, during which endometrium has been transformed from proliferative phase to secretory phase ${ }^{(6)}$. At this specific time period blood supply of uterus is rich and implantation is most likely to occur ${ }^{(\mathbf{1 1})}$.

There are various methods to assess the endometrial receptivity including endometrial biopsy and immunohistochemical analysis. The 
introduction of pulsed Doppler ultrasonography has provided a non-invasive mode of evaluation of uterine impedance and reveal physiological data, rather than anatomical information alone ${ }^{\mathbf{( 1 1 )}}$.

The measurement of impedance to uterine blood flow in IVF cycles has provided an indirect measure of endometrial receptivity ${ }^{(11)}$.

In studies where endometrial and subendometrial blood flow were analyzed by color or power Doppler ultrasonography absence of blood flow signal has been found to be associated with significantly low pregnancy rate or absence of pregnancy in IVF cycles ${ }^{(\mathbf{1 2})}$.

The current study is a case-control study done at Ain Shams University Maternity Hospital. And carried out during the period from June 2015 to April 2016. to evaluate the uterine perfusion, particularly the endometrial blood flow in women with unexplained infertility.

In this study we hypothesized that in women with unexplained infertility, endometrial perfusion may be unlike that of fertile women.

The patients recruited from women presenting to the outpatient clinic at Ain Shams University Maternity Hospital seeking fertility compared to other fertile group coming to hospital with non-specific gynecological problems or for routine checkup at the same period

The study conducted on two groups of women: Group1 (study group): 40 women with unexplained infertility. Group 2(control group): 20 fertile women who had normal physical and pelvic examination, regular menstrual cycles, didn't have intrauterine device or oral contraceptive, and gave a birth year ago.

The mean age of participant women in the study group was 26 years while in the control group the mean age of participant women was 27 . The mean BMI on participant women in the study group and in the control group were statistically insignificant $(\mathrm{P}=0.33$ and $\mathrm{P}=0.6$ respectively).

In a study carried out by Selda et al. $^{(11)}$., to assess the contribution of sub endometrial blood flow in the etiopathogenesis of unexplained infertility mid luteal- peri-implantation period spiral artery transvaginal color Doppler parameters were measured and compared with fertile controls.

The mean age of participant women in the study group was 26.7 years. While in the control group the mean age of participant women was 28.2 years.
The mean BMI on participant women in the study group was $25.4 \mathrm{~kg} / \mathrm{m}^{2}$. While in the control group was $25.6 \mathrm{~kg} / \mathrm{m}^{2}$.

In the current study as regard hormonal profile of the participant, mean of FSH level was 7.95 $\mathrm{mIU} / \mathrm{ml}$, mean $\mathrm{LH}$ level was $4.31 \mathrm{mIU} / \mathrm{ml}$ mean of prolactin level was 8.13 and the mean of mid luteal progesterone was $13.2 \mathrm{ng} / \mathrm{ml}$ in the study group, While of those in the control group mean of FSH level was $8.75 \mathrm{mIU} / \mathrm{ml}$,mean $\mathrm{LH}$ level was 4.01 $\mathrm{mIU} / \mathrm{ml}$, mean of prolactin level was 8.77 and the mean of mid luteal progesterone was $14.2 \mathrm{ng} / \mathrm{ml}$. From these results there is no statistically significant difference between both groups.

In study done by Selda $\boldsymbol{e t}$ al. ${ }^{\left({ }^{(1)}\right.}$., as regard hormonal profile of the participant, mean of FSH level was $7.6 \mathrm{mIU} / \mathrm{ml}$, and the mean of mid luteal progesterone was $10.86 \mathrm{ng} / \mathrm{ml}$ in the study group

While of those in the control group mean of FSH level was $7.58 \mathrm{mIU} / \mathrm{ml}$, and the mean of mid luteal progesterone was $10.84 \mathrm{ng} / \mathrm{ml}$. Both were statistically insignificant $(\mathrm{P}=0.099 \& 0.094$ respectively).

In the current study the mean the resistance index in the study group was 0.69 ranged from 0.39 to 0.96 , while the resistance index in the control group was 0.61 ranged from 0.58 to 0.73 and the difference between both groups was statistically significant as shown in table no. 5 this is comparable to study done by Selda et al ${ }^{(11)}$. In which resistance index in the study group was 0.54 , while the resistance index in the control group was $0.48(\mathrm{P}=0.009)$.

In the present study pulsatility index in the study group was 1.3 ranged from 0.51 to 1.99 while the pulsatility index in the control group was 1.16 ranged from 0.88 to 1.7 and this difference between both groups was statistically significant as shown in table no. 6, this was also comparable to results of study done by Selda et al ${ }^{(11)}$., pulsatility index in the study group was 0.8 while the pulsatility index in the control group was 0.7 and this difference between both groups was statistically significant $(\mathrm{P}=0.004)$.

These study results also went with Devyatova et $\boldsymbol{a l} .{ }^{\left({ }^{(9)}\right.}$. study that was done to evaluate of endometrial thickness and EBF with TVDUS in predicting the implantation in IVF cycles. And concluded that in his study, the pregnancy rate per ET was significantly higher $(63.1 \%$ versus $39.7 \%$ ) in the cases with the presence of EBF. 
Devyatova et $\boldsymbol{a l}{ }^{(9)}$., Similarly Steer et $\boldsymbol{a l} \boldsymbol{l}^{(4)}$. reported that $35 \%$ of women who failed to conceive in on IVF programme had a mean uterine artery PI value>3.0. Therefore, they suggested that embryo cryopreservation in those patients with a uterine artery PI>2.99 for transfer in subsequent cycles should be considered.

In other studies done by Steer $\boldsymbol{e t}$ al. ${ }^{(4)}$, that was done to assess whether a measure of uterine blood flow impedance (the pulsatility index, PI) as determined by transvaginal ultrasonography with color blood flow imaging, may be used to assess endometrial receptivity immediately before the time of embryo transfer (ET) after assisted conception and the prospective study done by Cacciatore $\boldsymbol{e t} \boldsymbol{a l} .{ }^{(13)}$. that was done to verify whether uterine artery impedance, measured as pulsatility index and resistance index is related to the outcome of in IVFET cycles, it was also found that there was significantly lower impedance at uterine artery blood flow in the conception group than in non-conception group in IVF-ET program. When spiral artery $\mathrm{RI}>0.72, \mathrm{PI}>1.6$ were present or there was absence of vascular signal in spiral artery, endometrium was considered to be non receptive, endometrial condition was suboptimal and implantation was unlikely to occur, so the patient was at high risk of ART treatment failure ${ }^{(4,13)}$.

Also, the results of the current study go with study done by Ari and his colleague ${ }^{(14)}$ that was done to evaluate whether endometrial and subendometrial blood flow parameters measured using three- dimensional power Doppler ultrasound (3D PD-US) can predict pregnancy after IUI and concluded that Three-dimensional PD-US was useful for evaluating endometrial and subendometrial neovascularization in IUI cycles. Endometrial blood flow parameters may be useful predictors for pregnancy ${ }^{(14)}$.

In the present study there is positive Correlation between resistance index, pulsatility index and all other parameters, except LH level there was negative correlation between its level and both resistance index, pulsatility index.as shown in table no 7.

From diagnostic Performance of PI and RI in Discrimination of patients and control, receiver operating characteristics (ROC) curve was used to define the best cut off value of: RI: which was $>0.67$, with sensitivity of $70 \%$ specificity of $75 \%$ positive predictive value of $85 \%$, negative predictive value of $60 \%$ with diagnostic accuracy of $69.7 \%$. PI: which was $>1.37$, with sensitivity of $77.5 \%$ specificity of $85 \%$ positive predictive value of $87 \%$, negative predictive value of $66 \%$ with diagnostic accuracy of $85.3 \%$.

From the results of our study we could say that uterine perfusion, particularly the endometrial blood flow in women with unexplained infertility is different from that in fertile women.

\section{CONCLUSION AND RECOMMENDATION}

The endometrial perfusion may have an important contribution to etiology of unexplained infertility. As unexplained infertility patients have high impedance blood flow in spiral arteries which means that peri-implantation blood flow in these patient is lower than fertile controls according to Doppler parameters, (pulsatility index $\&$ resistance index).

We recommend further study on large numbers of women and the possible role of perfusion enhancer's drugs in improving utero-ovarian circulation as a treatment of unexplained infertility.

\section{REFERENCES}

1. Fenning NJ, Campbell BK, Kendall NR et al. (2004): Endometrial and subendometrial perfusion are impaired in women with unexplained subfertility. Human Reproduction, 19: 2605.

2. Edi-Osagie EC, Seif MW, Aplin JD et al. (2004): Characterizing the endometrium in unexplained and tubal factor infertility: a multiparametric investigation. Fertil. Steril., 82: 1379-1389.

3. Goldberg BB, Liu JB, Kuhlman K et al. (1991): Endoluminal gynecologic ultrasound: preliminary results. J. Ultrasound Med., 10: 583-590.

4. Steer CV, Tan SL, Mason BA g et al. (1994): Midluteal-phasc vaginal color Doppler assessment of uterine artery impedance in a subfertile population. Fertil. Steril., 61, 53-58.

5. Battaglia C, Sgarbi L, Salvatori $M$ et al. (1998): Increased anticardiolipin antibodies are positively related to the uterine artery pulsatility index in unexplained infertility. Human Reproduction, 13: 3487-3491.

6. Gong $X$, Li $Q$, Zhang $Q$ et al. (2005): Predicting Endometrium Receptivity with parameters of spiral artery blood flow. Journal of Huazhong Universty of Science and Technology, 25:335-338. 
7. Guzman ER, Kontopoulos E and Zalud I (2005): Doppler velocimetry of the Ueroplacental Circulaion. In: Doppler Ultrasound in Obstetrics and Gynecology. $2^{\text {nd }}$ edi; Dev Maulik (ed).

8. Napolitano R, Melchiorre K, Arcangeli T et al. (2012): Screening for pre-eclampsia by using changes in uterine artery Doppler indices with advancing gestation. Prenat. Diagn., 32(2):180-184

9. Devyatova EA, Tsaturova KA and Vartanyan EV (2016): Predicting of successful implantation at IVF cycles. Gynecol. Endocrinol., 32(2): 27-29.

10. Practice Committee of the American Society for Reproductive Medicine. (2008): Definitions of infertility and recurrent pregnancy loss. Fertil. Steril., 89:1603.

11. Selda U, Elif P, Tekin E et al. (2012): Endometrial spiral artery Doppler parameters in unexplained infertility patients: is endometrial perfusion an important factor in the etiopathogenesis?. J. Turkish-German Gynecol. Assoc., 13: 169-171.
12. Chien LW, Au HK, Chen PL et al. (2002): Assessment of uterine receptivity by the endometrial-subendometrial blood flow distribution pattern in women undergoing in vitro fertilization-embryo transfer. Fertil. Steril., 78:245-251.

13. Cacciatore B, Simberg $N$, Fusaro $P$ et al. (1996): Transvaginal Doppler study of uterine artery blood flow in in vitro fertilization-embryo transfer cycles. Fertil. Steril., 66: 130-134.

14. Ari K, Tae $K$ and Sang $W$ (2010): Relationship between endometrial and subendometrial blood flow measured by threedimensional power Doppler ultrasound and pregnancy after intrauterine insemination, Fertil. Steril., 94:747-752. 